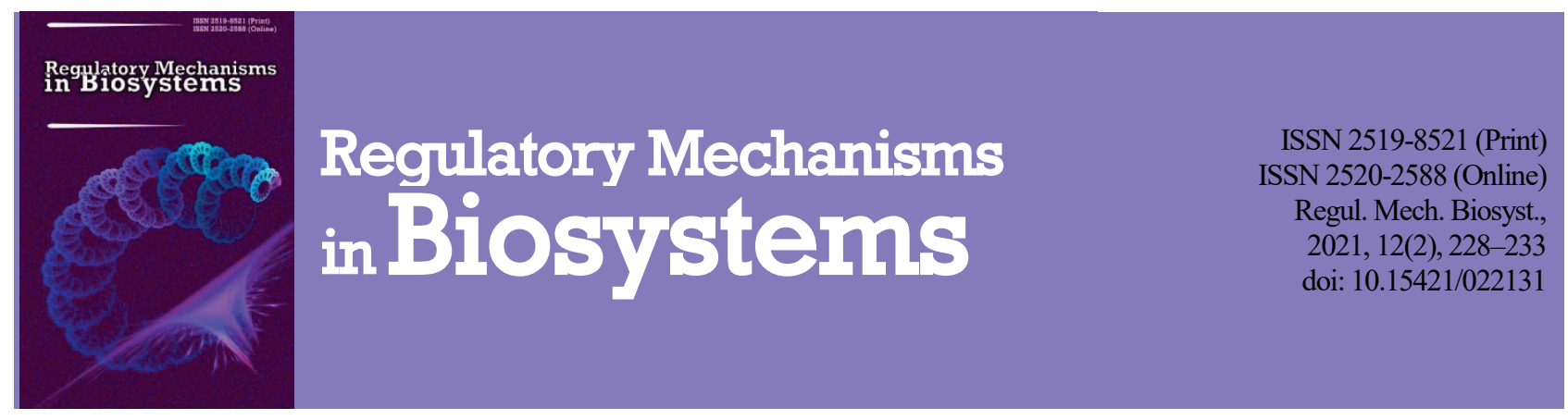

\title{
Etiological factors in triggering non-specific allergic reactions to tuberculin in cattle
}

\author{
A. I. Zavgorodnii*, S. A. Pozmogova*, M. V. Kalashnyk*, A. P. Paliy*, L. V. Plyuta**, A. P. Palii*** \\ *Institute of Experimental and Clinical Veterinary Medicine, Kharkiv, Ukraine \\ **Sumy National Agrarian University, Sumy, Ukraine \\ ***Kharkiv Petro Vasylenko National Technical University of Agriculture, Kharkiv, Ukraine
}

Received 09.04.2021

Received in revised form

11.05.2021

Accepted 14.05.2021

Institute of Experimental and

Clinical Veterinary Medicine

Pushkinska st., 83,

Kharkiv, 61023. Ukraine

Tel.: +38-050-681-81-85. E-mail:

nick.v.kalashnik@gmail.com

Sumy National Agrarian

University, Gerasim Kondratieva

st, 160, Sumy, 40021, Ukraine.

Tel.: +050-718-06-77.

E-mail:pljuta@ukr.net

Kharkiv Petro Vasylenko

National Technical University

of Agriculture, Alchevskyhst., 44 ,

Kharkiv, 61002, Ukraine.

Tel.: +38-063-712-82-42.

E-mail:paliy.andriy@ukr.net

\section{Introduction}

In veterinary and human medicine paraallergy is very common and has a persistent tendency to spread, as evidenced by scientific publications (Michel, 2008; Dodd et al., 2010). Atypical mycobacteria are known to cause non-specific reactions to tuberculin (Nuru et al., 2017). At the same time, microorganisms that have a genetic, immunological and chemotaxis affinity with mycobacteria may circulate in an animal's body. These microorganisms can also cause the sensitization of the macroorganism to tuberculin (Basybekov et al., 2018; Zavgorodnii et al., 2018).

Unjustified slaughter of healthy animals with non-specific reactions to tuberculin causes economic losses in the livestock sector. Therefore, determining the nature of allergic reactions remains a relevant and important aspect in the differential diagnosis of tuberculosis (Jones et al., 2010; Vordermeier et al., 2011). Aerobic and anaerobic bacteria combined in the order Actinomycetales are capable of sensitizing the macroorganism. They are phylogenetically diverse but morphologically similar (McNeil \& Brown, 1994). Aerobic actinomycetes such as Nocardia, Gordona, Tsukamurella, Streptomyces, Rhodococcus, streptomycetes, mycobacteria and corynebacteria are a group of gram-positive bacteria with filamentous branching structures. They are also divided into bacterial or coccoid forms. Genetically and immunologically related genera Nocardia and Rhodococcus, which have a mycelial stage in their development cycle, are combined into the group nocardioform actinomycetes (Goodfellow \& Maldonado, 2006; Sullivan \& Chapman, 2010). The mycobacteria, Nocardia and Rhodococcus are characterized by their unique chemical composition and cellular wall structure, which are represented by peptidoglycans, fatty acid chains and neutral arabinogalactan polysaccharide. Arabinogalactan

\begin{abstract}
(avgorodnii, A. I., Pozmogova, S. A., Kalashnyk, M. V., Paliy, A. P., Plyuta, L. V., \& Palii, A. P. (2021). Etiological factors in
\end{abstract}
The article presents the results of allergic and bacteriological studies of cattle from a tuberculosis-free farm. The presence of cattle reacting to an allergen from atypical mycobacteria was established in three allergic simultaneous tests during 2019-2020. Based on the results obtained, the causative agent of tuberculosis and atypical mycobacteria were not isolated during the bacterioms were also isolated from the soil and straw samples. Short-term non-specific reactions in cattle to mycobacterial allergens were due to the persistence and circulation of the aforementioned microorganisms closely related to mycobacteria. It was deter-
mined that the genera Nocardia and Rhodococcus are sensitive to the $1.0 \%, 2.0 \%, 3.0 \%$ solutions of glutaraldehyde, formaldehyde and sodium hydroxide. Thus, it is necessary to take into account the epizootic situation as to the presence of nocardioform microorganisms in the herd during routine allergic studies, as well as in case of differentiation between specific reactions and peudoallergic ones. It is necessary to carry out comprehensive systematic studies of livestock and feed quality Keywords: allergens; identification; non-specific reactions; Actinomyces spp.; Nocardia spp.; Rhodococcus spp.; disinfectant.

is a group-specific antigen (Gürtler et al., 2004; Brown-Elliott et al., 2006) The genus Actinomyces includes a group of 42 species and 2 subspecies. This genus is composed mainly of anaerobic microorganisms (Parte et al., 2020). The Actinomyces bovis causes actinomycosis in cattle (Masand et al., 2015).

Atypical mycobacteria, nocardia and rhodococci belong to the order Actinomycetales. They are very common in the environment and are also isolated from biological material (Tkachenko et al., 2016; Medo et al., 2019; Sapkota et al., 2020).

The characteristic feature of infections caused by microorganisms of the order Actinomycetales is a chronic disease, granulomatous (nocardiosis and rhodococcosis) or pyogranulomatous (actinomycosis) process in a macroorganism leading to formation of abscesses and fibrosis in various organs and tissues (Gajdács \& Urbán, 2020). Animals rarely recover without an appropriate therapy. Clinical signs in cattle and companion animals are characterized by mastitis, skin and subcutaneous lesions, abscesses in organs and tissues, as well as bronchial-pulmonary lesions. The above-mentioned signs caused by Actinomycetales depend on the localization of the inflammatory process, the degree of virulence of the pathogen and the resistance of the organism of susceptible animals. Osteomyelitis and abortions are present at the stage of generalization of the process. Nocardia asteroidesis is the main causative agent of nocardiosis in livestock (Mahendra \& Dave, 2016). Rhodococcus equi is the etiological agent of rhodococcosis in animals and humans in most cases (Vordermeier et al., 2011; Giguère et al., 2011).

According to literary sources, mass gastrointestinal and respiratory diseases of calves were detected on tuberculosis-free farms and recorded. Tuberculin-positive animals were present on these farms. It should be 
noted that nocardioform actinomycetes were the causative agents of the above-mentioned diseases (Van Metre et al., 2008). A septic process in goats was initiated by Rhodococcus equi and described in another study (Jeckel et al., 2011). In human medicine a high mortality rate $45-85 \%$ is mainly seen among patients with pronounced immunodeficiency when nocardiosis and rhodococcosis are present. Lethal cases have also been reported among immunocompetent patients. The proportion of patients without immunodeficiency accounts for no more than $10-15 \%$ of cases (Kamboj et al., 2005; Yamshchikov et al., 2010). The ubiquitous distribution of representatives of the genus Actinomyces poses a serious threat to the treatment of the diseases they cause (Siavashifar et al., 2021).

The control and prevention of infectious diseases implies and requires the use of a number of antimicrobial agents, including disinfectants (Paliy et al., 2016; West et al., 2018). The pharmaceutical industry has developed and proposed a number of disinfectants that differ in chemical composition, physicochemical, toxicological and bactericidal properties (Zazharskyi et al., 2019, 2020). However, the use of a particular disinfectant for a specific infectious disease presupposes its preliminary testing to determine the effectiveness on the pathogen, as well as the modes of usage (Mc Carlie et al., 2020). It should be borne in mind that the constant use of the same disinfectant leads to the formation of altered resistant forms of mycobacteria (Shinoda et al., 2016). Only a complex of general economic, special diagnostic and veterinary and sanitary measures allows us to control the epizootic situation and obtain high-quality products of animal origin (Shkromada et al., 2019).

The aim of the research was to determine the cause of non-specific allergic reactions to mycobacterial allergens in cattle. Isolation and identification of the etiological agent and its ability to sensitize the macroorganism and resistance to reference disinfectants were taken into account.

\section{Materials and methods}

The research on cattle was carried out by the allergic method on a tuberculosis-free farm during the spring and autumn of 2019, as well as in the spring of 2020. Animals that react to mycobacterial allergens are detected annually during routine allergic skin tests. Eight hundred and ninety-six head of cattle have been examined in the allergen simultaneous test, including 526 cows, 50 heifers, 320 young over 2 months old in spring 2019. Five hundred and fifty-two animals were examined, including 413 cows and 132 young in the autumn of the same year. Eight hundred and seventy-two animals were tested including 523 cows, 46 heifers and 303 young during the spring of 2020. Allergic study was carried out using the following drugs "Purified tuberculin (PPD) for mammals in a standard solution" and "Dry purified allergen from atypical mycobacteria" (AAM) (produced by the state enterprise "Sumy Biofabrika", Ukraine, in 2019). Tuberculin was injected intradermally with a needleless injector "BI-7" on the left side of the middle third of the neck in a place previously clipped and treated with $70 \%$ ethanol at a dose of $0.1 \mathrm{~cm}^{3}$. An allergen from atypical mycobacteria was injected on the right side of the neck. The examination of skin reactions was carried out 72 hours after the injection of allergens by measuring the thickness of the skin fold. A skin test was considered positive if the difference was $3.0 \mathrm{~mm}$ or more between normal skin thickness and its thickness after the injection of allergens.

Biological material was studied by bacteriological method (Ramos et al., 2015). Samples were taken from retropharyngeal, submandibular, bronchial, mediastinal lymph nodes, liver, spleen, lungs from 17 animals reacting to mycobacterial allergens, as well as soil samples $(n=5)$ from environmental objects and straw $(n=5)$.

Preliminary treatment of biological material was carried out in accordance with A. P. Alikaeva's method using a $6.0 \%$ solution of sulfuric acid. Feed (straw) and soil samples were treated by $0.9 \%$ solution of cetylpyridinium chloride. The inoculation of the samples was conducted on a solid egg nutrient medium "Dry nutrient medium for the cultivation of mycobacteria" (OOO NDP "Veterinary Medicine", Ukraine, 2019) with further cultivation in a thermostat at a temperature of $37.5 \pm 0.5^{\circ} \mathrm{C}$ during three months. A microbial growth analysis and record performed and kept on a daily basis during the first week and once a week thereafter. If the colonies of microorganisms on a slant of the nutrient medium were isolated, generic identification was carried out. Bacterioscopic, culture and biochemical tests were used to differentiate Rhodococcus from Nocardia species. Acid fastness, cell morphology, the presence or absence of mycelium were discovered by microscopy of smears made from isolated cultures of microorganisms, stained by the Ziehl-Neelsen. A number of parameters were analyzed and determined in the culture tests, such as the rate of appearance of the primary growth of colonies, their pigmentation and morphology, the presence of aerial mycelium, the ability of isolates to grow at various temperature conditions $\left(25,37,45^{\circ} \mathrm{C}\right)$, as well as growth on media with the addition of $5.0 \%$ sodium chloride and sodium salicylate at a concentration of $1000 \mu \mathrm{g} / \mathrm{cm}^{3}$. In addition, among the isolates distinguished, we found amidase, arylsulfatase (after 14 days) and catalase activity, the ability to hydrolyze tween 80 and reduce potassium tellurite. For this reason, a culture suspension was prepared at a concentration of $1.0 \mathrm{mg}$ of the bacterial mass in $1.0 \mathrm{~cm}^{3}$ of sterile $0.85 \%$ sodium chloride solution and inoculated in $0.5 \mathrm{~cm}^{3}$ on a nutrient medium for each test separately.

The sensitizing properties of isolated microorganisms were studied on experimentally infected guinea pigs ( 3 animals for each culture) in an allergy test. The tuberculin (PPD) for mammals and AAM were used for this study 30 and 60 days after infecting the laboratory animals. A sterile isotonic sodium chloride solution was injected into animals from the control group $(\mathrm{n}=3)$. Experiments on animals were carried out in accordance with modern bioethical requirements (Festing \& Wilkinson, 2007; Kabene \& Baadel, 2019).

The resistance of field isolates of nocardioform actinomycetes of the genus Nocardia, Rhodococcus to $1.0 \%, 2.0 \%, 3.0 \%$ solutions of sodium hydroxide, formaldehyde, and glutaraldehyde was studied by the suspension method (Paliy et al., 2020). The bacterial mass of each culture was separately added into sterile $20.0 \mathrm{~cm}^{3}$ vials. Then $1.0 \%, 2.0 \%, 3.0 \%$ alkali solutions, formaldehyde and glutaraldehyde were added in a volume of $10.0 \mathrm{~cm}^{3}$. The contents of the vials were thoroughly mixed with sterile glass rods and kept at a temperature of $18{ }^{\circ} \mathrm{C}$ with 3,5 and 24-hour exposure. After that, the contents of each vial with a volume of $2.5 \mathrm{~cm}^{3}$ were collected with a separate bacteriological pipette and transferred to centrifuge tubes. The centrifugation mode was $3000 \mathrm{rpm}$ within 15 minutes. The resulting precipitate was washed twice with sterile saline by centrifugation. After that, the pellet was resuspended in $4.0 \mathrm{~cm}^{3}$ of sterile saline and inoculated on a solid nutrient medium in four tubes. The inoculated tubes were cultured in a thermostat at $37.5 \pm 0.5^{\circ} \mathrm{C}$ for 20 days. The analysis and record of the growth of cultures on experimental and control tubes was performed and kept every $3-5$ days.

\section{Results}

It was found that 26 animals reacted in a simultaneous test out of 896 studied in spring 2019 according to the results of the allergy study. Twelve animals repeated allergic reactions. At the same time, intradermal reactions to AAM were more intensive in comparison with reactions to tuberculin (PPD) for mammals in most cases $(n=22)$. The mean of intensity of the reactions was $6.9 \pm 1.3 \mathrm{~mm}$, namely the increase in the thickness of the skin after the injection of allergens in comparison with the normal thickness on the AAM. This value for PPD was $4.1 \pm 0.6 \mathrm{~mm}$. The intensity of reactions to both allergens was the same in 4 cows. Ten reactive animals were identified in autumn of the same year. The response to PPD was greater than to AAM in one cow. Mean values of the intensity of reactions to PPD were less than to AAM in 9 other animals and amounted to $4.3 \pm$ 1.1 , and $7.4 \pm 2.9$, respectively. Fifteen reacted cows were found during studies of cattle herd in spring 2020. The mean intensity of responses to $\mathrm{AAM}$ was $7.6 \pm 2.7 \mathrm{~mm}$ and $4.0 \pm 0.9 \mathrm{~mm}$ compared with responses to PPD in 12 animals from this group (Table 1).

Seventeen reacted animals were slaughtered for diagnostic purposes. Macroscopic lesions characteristic for tuberculosis were not detected in the internal organs and tissues according to the results of the postmortem examination. However, there was an enlargement of pharyngeal and submandibular lymph nodes, presence of abscesses and cysts. There were granulomas with necrobiotic changes with the presence of purulent exudate in some animals. The granulation tissue turned fibrous along the periphery of abscesses without signs of calcification. Hemorrhages were observed in some cases. The lymph nodes were yellowish due to yelloworange exudate in five samples (Fig. 1). 
Table 1

The results of allergic studies of animals for tuberculosis

\begin{tabular}{|c|c|c|c|c|c|c|}
\hline \multirow[b]{2}{*}{ Date } & \multirow{2}{*}{ Number of studied animals } & \multirow{2}{*}{ Number of reacted animals } & \multicolumn{3}{|c|}{ The intensity of reactions } & \multirow[b]{2}{*}{ Number of slaughtered animals } \\
\hline & & & PPD $>$ AAM & $\mathrm{PPD}<\mathrm{AAM}$ & $\mathrm{PPD}=\mathrm{AAM}$ & \\
\hline 18.03.2019 & 896 & 26 & - & 22 & 4 & 5 \\
\hline 11.10.2019 & 552 & 10 & 1 & 9 & - & 6 \\
\hline 20.03 .2020 & 872 & 15 & - & 12 & 3 & 6 \\
\hline
\end{tabular}
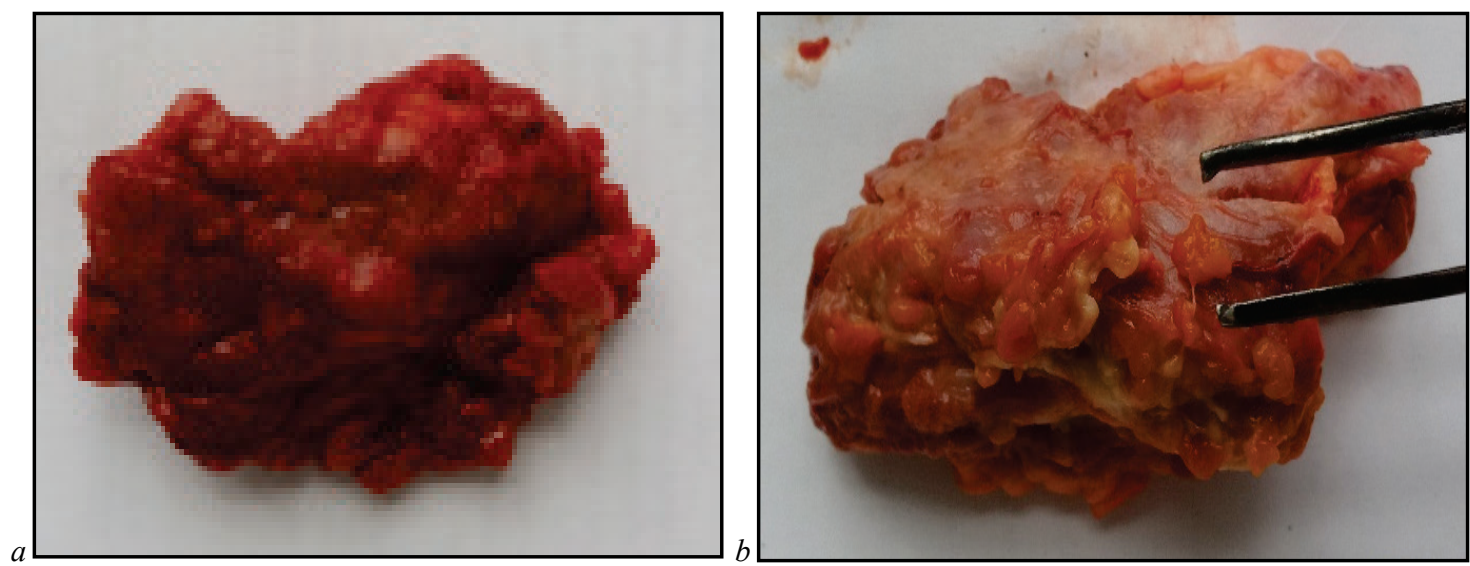

Fig. 1. Actinomycosis: $a$-the pharyngeal lymph node; $b$-submandibular lymph node

Bronchial and mediastinal lymph nodes were without visible lesions in all samples. Actinomyces druses in the form of grey unstained particles, accumulations of tangled and branched fibers, blue mycelium with bulbous thickenings on the periphery, as well as various accompanying microflora were detected in the mucopurulent contents of softened foci during bacterioscopic examination of smears from the retropharyngeal and submandibular lymph nodes (Fig. 2). The growth of round, convex, shiny white colonies was observed on the solid egg nutrient medium after 57 days of cultivation. Filamentation of mycelium into non-acidic rod-shaped forms of various lengths and presence of cocci were identified in smears from colonies stained according to Ziehl-Neelsen by oil immersion microscopy (Fig. 3). Over time, this microflora decomposed the solid egg nutrient medium, which was made for cultivating mycobacteria, to a liquid state with a specific smell of hydrogen sulfide.

The isolated microorganisms were assigned to the genus Actinomyces on the basis of the presence of characteristic pathological lesions in the lymph nodes and according to the results of culture and bacterioscopic studies.

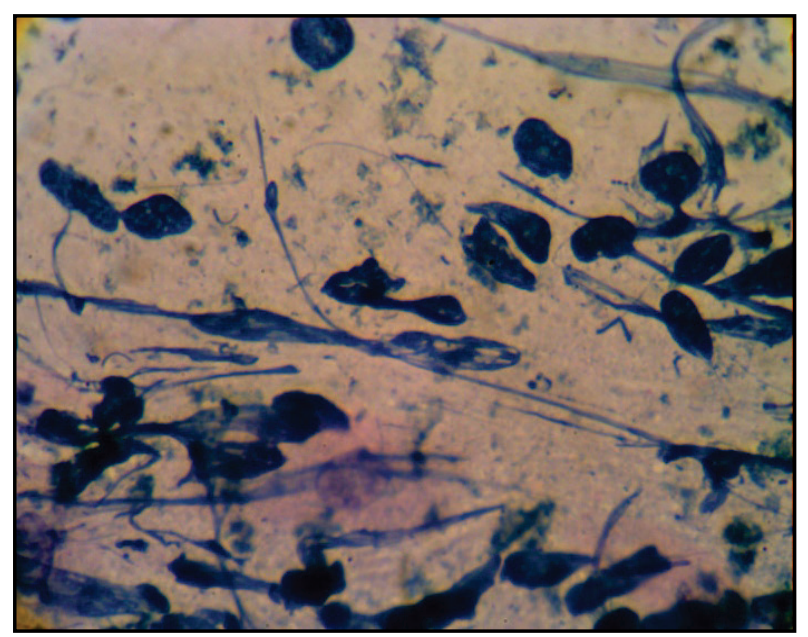

Fig. 2. Filamentous mycelium with thickenings from Smear of the retropharyngeal lymph node

Cultures of microorganisms partially acid-fast and related to mycobacteria were also isolated from diagnostic material from 12 cows of this farm apart from the above mentioned actinomycetes.
Polymorphic structures were detected in smears from the pharyngeal lymph nodes from these cows during a microscopy examination. There were filamentous-branched mycelium, acid-fast and non-acid-fast bacilli and cocci that were located outside the cells and intracellularly.

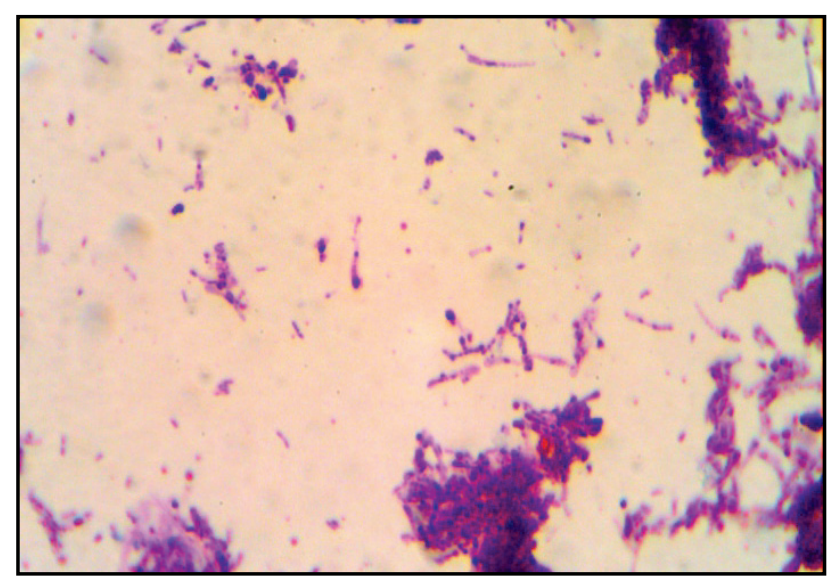

Fig. 3. Fragmentation of mycelium into sticks: Smear the nutrient medium surface

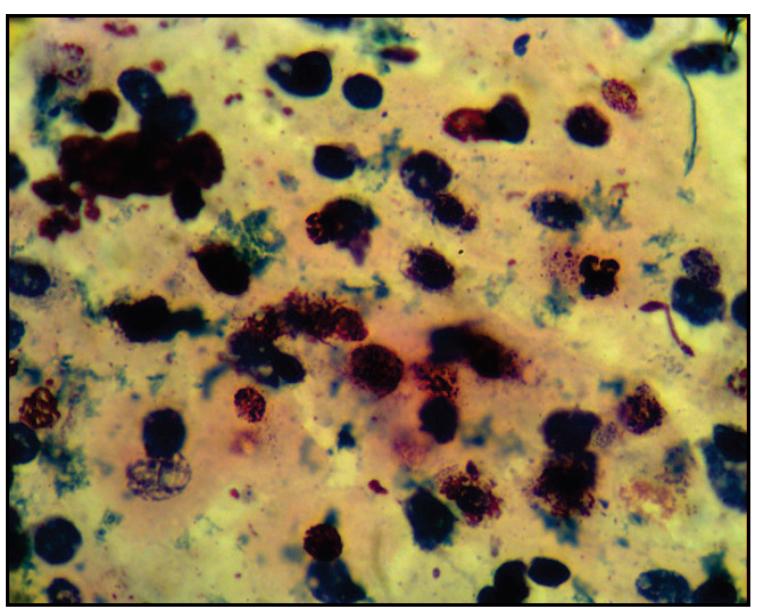

Fig. 4. A Smear of the retropharyngeal lymph node 
As a result, macrophages with bacteria were red (Fig. 4). Two types of colonies of microorganisms were isolated according to the results of the cultural study of these samples on an egg nutrient medium. Thus, the primary growth of microorganisms was presented in the form of light yellow or yellow, smooth, shiny, colonies without superficial mycelium. The samples were taken from 10 cows after 7-10 days of cultivation. Short acid-fast and non-acid-fast bacilli and cocci were detected in smears from cultures stained by Ziehl-Neelsen. Micellar forms were not observed in the field of view (Fig. 5).

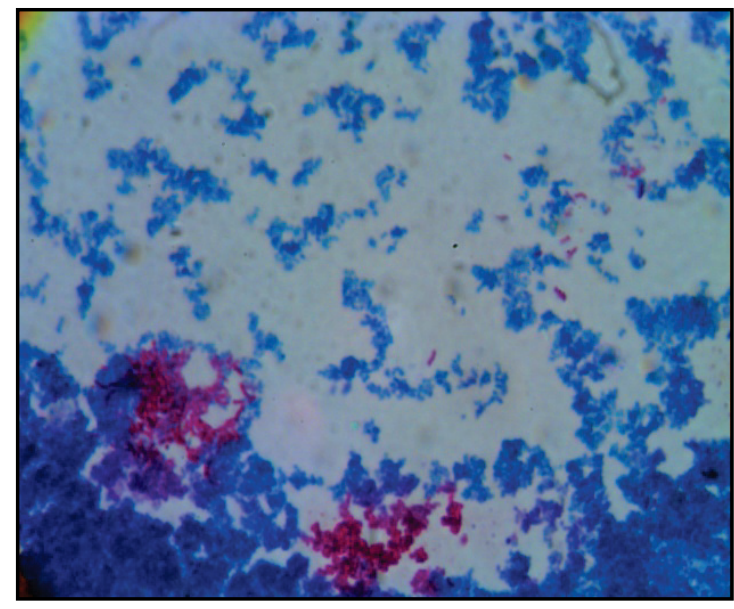

Fig. 5. Smear from the culture of rhodococci: acid-fast and non-acid-fast bacilli and cocci

It was found that the optimum temperature for the growth of these bacteria was $25-38^{\circ} \mathrm{C}$ when determining the cultural and biochemical parameters of culture isolates. No growth was observed at a temperature of $45^{\circ} \mathrm{C}$. Also, there was no growth of colonies on a medium with sodium salicylate $\left(1000.0 \mu \mathrm{g} / \mathrm{cm}^{3}\right)$. But these microorganisms were cultured on a medium with $5.0 \% \mathrm{NaCl}$, where the colonies became bright orange. The cultures had high amidase activity. They were catalase-positive, and did not hydrolyze tween 80 . Potassium tellurite was reduced on the third day and phenolphthalein was not renewed in the arylsulfatase test on the 14th day. On the basis of bacteriological research, it was found that isolated microorganisms $(n=10)$ belong to the common with mycobacteria phylogenetic group of nocardioform actinomycetes of the genus Rhodococcus.

It was found that the primary growth of two other isolated cultures of microorganisms appeared on the fifth day in the form of small, smooth, moist, yellow colonies on the surface of the nutrient medium. These colonies had a rough, dull and wavy surface with uneven edges and a brittle texture. They had a bright orange or terracotta colour after 12-15 days of cultivation (Fig. 6). Filamentous-branched mycelium was detected in firstgeneration cultures in microscopy of smears stained by Ziehl-Neelsen. It has been fragmented into pleomorphic acid-fast (red) and non-acid-fast (blue) granular bacilli and coccoid forms in the second passage (Fig. 7). The accompanying microflora was not detected by microscopy. It should be noted that these microorganisms lost their acid resistance in further passages.

It was found that these microorganisms grew at a temperature of $25^{\circ} \mathrm{C}$ and $37-38^{\circ} \mathrm{C}$, and did not grow at a cultivation temperature of $45^{\circ} \mathrm{C}$ when studying their culture and biochemical properties. Microorganisms were tolerant to sodium salicylate at a concentration of $1000 \mu \mathrm{g} / \mathrm{cm}^{3}$ in the nutrient medium and $5.0 \%$ sodium chloride. They had negative reactions to nicotinamidase and catalase, had arylsulfatase activity, did not hydrolyze tween 80 , were urease-positive, and partially reduced potassium tellurite to metallic tellurium on the 21st day. On the basis of the studies conducted, cultures of microorganisms were isolated and assigned to nocardioform actinomycetes of the genus Nocardia.

The second part of the work was devoted to the study of soil and straw samples taken from the territory of the farm. For this reason, the experimental samples were preliminarily treated with a $0.9 \%$ solution of cetylpyridinium chloride with 20-hour exposure and inoculated on a nutrient medium made for cultivating mycobacteria.

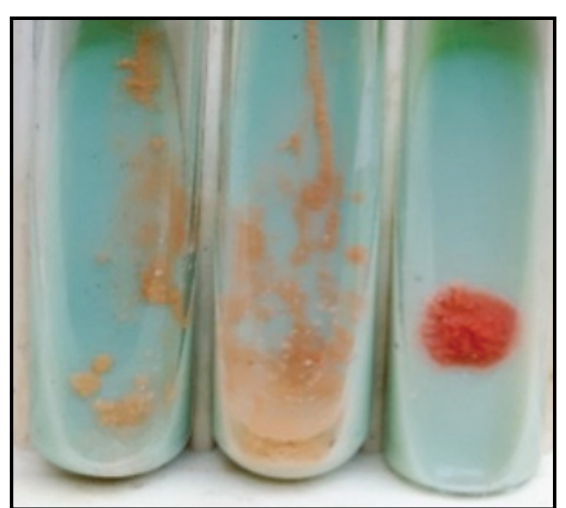

Fig. 6. Colonies of nocardia on solid nutrient medium

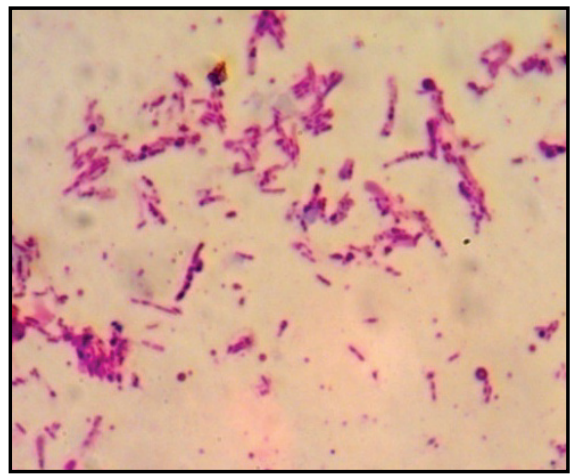

Fig. 7. Nocardia: second passage, fragmentation into bacilli and cocci

After 5-10 days the growth of slimy, shiny white, yellow and opaque orange colonies with superficial mycelium was observed in all soil and straw samples on a nutrient medium made for cultivating mycobacteria. Partially acid-fast granular bacilli, cocci, and mycelium were detected by microscopy of smears from isolated cultures stained according to ZiehlNeelsen. Based on the results of studying the cultural and biochemical characteristics, the cultures were identified as microorganisms of the genera Actinomyces, Nocardia and Rhodococcus.

Double subcutaneous injection of a suspension of the isolated cultures caused short-term sensitization to tuberculin for mammals and AAM at a dose of $2.0 \mathrm{mg} / \mathrm{cm}^{3}$ in isotonic solution after 30 days. At the same time, myxomas were found in guinea pigs in the form of dense tumours up to $2.0 \mathrm{~cm}$ in size with purulent contents at the site of inoculation of Nocardia and Rhodococcus cultures. Also, hyperplasia of the inguinal lymph nodes and spleen was present.

Thus, the isolation of ubiquitous microorganisms from samples of biological material, straw and soil indicates an exogenous route of their entry and circulation in the body of cattle.

Determination of the resistance of isolated cultures to disinfectants was the next stage of the research (Table 2).

Table 2

Resistance of Nocardia spp. and Rhodococcus spp. to disinfectants ( $\mathrm{n}=5$ )

\begin{tabular}{|c|c|c|c|c|c|c|c|c|c|c|c|}
\hline \multirow{3}{*}{ Isolate } & \multirow{3}{*}{$\begin{array}{l}\text { Exposure, } \\
\text { hours }\end{array}$} & \multicolumn{3}{|c|}{$\mathrm{NaOH}$} & \multirow{2}{*}{\multicolumn{3}{|c|}{$\begin{array}{l}\text { Formaldehyde } \\
\text { concentration, \% }\end{array}$}} & Glut: & aralde & hyde & \multirow{3}{*}{ Control } \\
\hline & & & & & & & & & & & \\
\hline & & 1.0 & 2.0 & 3.0 & 1.0 & 2.0 & 3.0 & 1.0 & 2.0 & 3.0 & \\
\hline \multirow{3}{*}{$\begin{array}{l}\text { Nocardia } \\
\text { spp. }\end{array}$} & 3 & + & + & - & - & - & - & - & - & - & \multirow{3}{*}{+} \\
\hline & 5 & + & + & - & - & - & - & - & - & - & \\
\hline & 24 & - & - & - & - & - & - & - & - & - & \\
\hline \multirow{3}{*}{$\begin{array}{l}\text { Rhodo- } \\
\text { coccus spp. }\end{array}$} & 3 & + & + & + & - & - & - & - & - & - & \multirow{3}{*}{+} \\
\hline & 5 & + & + & + & - & - & - & - & - & - & \\
\hline & 24 & - & - & - & - & - & - & - & - & - & \\
\hline
\end{tabular}

The growth of colonies on the surface of the nutrient medium was established on the 3rd day in the form of separate colonies (10-12 colonies) with typical growth for these microorganisms under a study of resistance of field isolates of the genus Nocardia to the action of a $1.0 \%$ alkali solution with 3-hour exposure. The number of colonies increased to 20-30 
after 7 days of cultivation (Fig. 8). Primary growth of 3-5 colonies was established on the 12th day when these microorganisms were in a $2.0 \%$ alkali solution with 5-hour exposure. The number of colonies increased to 10-12 units on the 20th day of cultivation (Fig. 9).

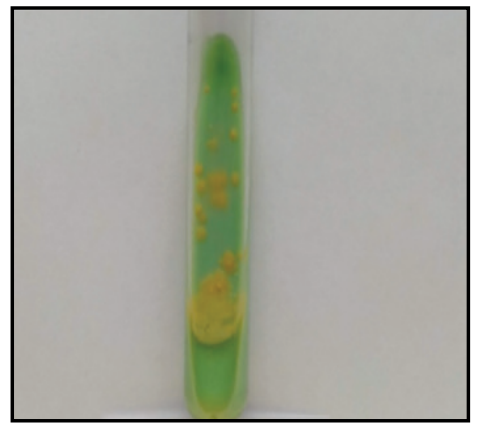

Fig. 8. Growth of Nocardia spp. after treatment with $1.0 \% \mathrm{NaOH}$ at one hour exposure

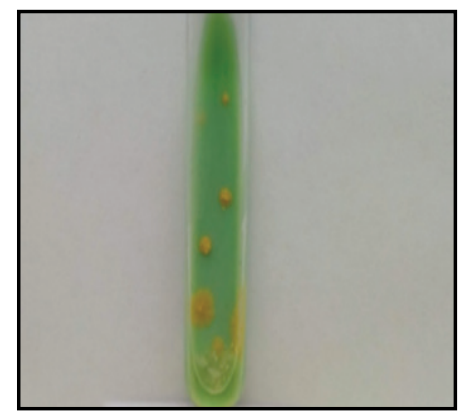

Fig. 9. Growth of Nocardia spp. after treatment with $2.0 \% \mathrm{NaOH}$ at 5 hours exposure

The growth of colonies was observed on the 5-8th days of cultivation when studying the resistance of isolates of the genus Rhodococcus to $1.0 \%, 2.0 \%, 3.0 \%$ alkali solution with 3-5-hour exposure. The number of colonies was more than 80 units on the 20th day of cultivation (Fig. 10).

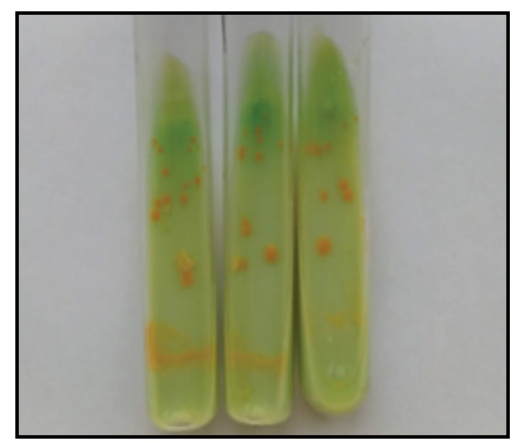

Fig. 10. Growth of Rhodococcus spp. after preliminary treatment with $1.0 \%, 2.0 \%, 3.0 \%$ solutions of $\mathrm{NaOH}$ at 3 hours exposure

The growth of viable microorganisms on the nutrient medium was not found when using the $1.0 \%, 2.0 \%, 3.0 \%$ alkali solution with 24 -hour exposure. The growth of these microorganisms wasn't established after soaking nocardia and rhodococci in 1.0\%, 2.0\%,3.0\% formaldehyde, glutaraldehyde solutions with 3, 5 and 24-hour exposure. This fact indicates the presence of the bactericidal effect of these solutions.

\section{Discussion}

Diagnosis of tuberculosis remains an urgent task for veterinary medicine worldwide (Ramos et al., 2015; Averill et al., 2020). The issues of paraallergic and pseudoallergic reactions to tuberculin remain not fully clarified in animals from tuberculosis-free farms in Ukraine. In addition to this, methods for differentiating specific reactions from paraallergic and pseudoallergic ones to tuberculin require further improvement. Despite the fact that cattle herds in Ukraine have been rehabilitated from tuberculosis since October 2016, allergic monitoring studies of tuberculosis-free farms found annually upwards of 10-40 animals reactive to tuberculin (Zavgorodnii et al., 2018). We identified 51 animals that reacted to PPD tuberculin for mammals and AAM in our study conducted during 2019-2020. The intensity of the reaction was more pronounced for AAM in 43 reacting animals. Seven animals reacted with the same intensity of reactions to both allergens. The intensity of the response to tuberculin was greater than to AAM in one cow only.

Correct identification of the order Actinomycetales is the most important aspect of diagnosis, taking into account the species diversity of these microorganisms and the wide range of diseases in which they are isolated (Singh et al., 2016; Njenga et al., 2017; Sapkota et al., 2020). Generic identification using cultural and bacterioscopic methods still remains the "gold standard" of laboratory diagnostics, since the clinical signs and symptoms of diseases caused by Actinomycetales are not specific and pathognomonic (Ramos et al., 2015). The diagnosis of actinomycosis was confirmed in 5 out of 17 samples from slaughtered animals based on the results of bacteriological studies. Microorganisms of the genus Rhodococcus ssp. were isolated in 10 samples. Cultures of Nocardia ssp. were also isolated from two animals. At the same time, pathological changes characteristic for tuberculosis were not identified in any case. Similar results were obtained by other researchers (Nalapa et al., 2017). Microorganisms of the genera Nocardia, Rhodococcus and Actinomyces were also isolated from soil and straw samples collected on the farm. This indicates the wide spread and, as a consequence, the circulation and persistence of these pathogens among cattle on the studied farm.

The studies carried out made it possible to consider the above-described microorganisms as a probable cause of the presence of non-specific sensitization to mycobacterial allergens. According to the results of the studies, it was found that guinea pigs infected with Nocardia and Rhodococcus reacted to PPD-tuberculin for mammals and to AAM. Allergic reactions persisted for a short period of time.

Based on the obtained research results, it has been established that sensitization of animals on the examined farm was due to animals being infected with microorganisms of the order Actinomycetales.

Given the fact that the external environment is the primary source of animals infected with Actinomycetales microorganisms, it should be expected that the existence of these pathogens as ecological species on a farm will ensure their constant transmission through contaminated water, feed or equipment. Therefore, there is a high risk of developing an infectious pathology. The presence of sensitization of animals to mycobacterial allergens is a consequence of this.

On the basis of the above considerations, an important aspect in the interruption of the epizootic chain is the timely detection of the infectious agent, as well as the implementation of preventive disinfection and sanitary-hygienic measures (Bocian et al., 2014). For this purpose, the resistance of the isolated cultures of nocardioform actinomycetes to the action of disinfecting solutions of sodium hydroxide, formaldehyde and glutaraldehyde was studied. These chemical compounds are widely used in world disinfection practice (Sicuro, 2016; Pearlman, 2019; Kindermann et al., 2020). According to our studies, solutions of formaldehyde and glutaraldehyde had the most pronounced bactericidal properties. Thus, $1.0 \%$ solutions of the above-mentioned aldehydes devitalized Nocardia ssp. and Rhodococcus ssp. isolates within 3 hours. Alkali solutions were ineffective in concentrations $1.0 \%, 2.0 \%, 3.0 \%$ with 3 and 5 -hour exposure. However, these solutions had a bactericidal effect against Nocardia and Rhodococcus when exposed for 24 hours. The use of environmentally friendly and safe antimicrobial drugs is a promising area (Zazharskyi et al., 2020).

\section{Conclusions}

Isolation of microorganisms of the genera Nocardia, Rhodococcus and Actinomyces from biological material samples from cattle and from environmental objects (soil and straw) indicates the presence of an exogenous route of entry into the body, as well as the persistence and circulation of these closely related microorganisms in animals and on farms. This is the main reason for non-specific reactions in cattle to mycobacterial allergens in the diagnosis of tuberculosis. It is advisable to use $1.0 \%$ solutions 
of glutaraldehyde or formaldehyde with 3-5-hour exposure to decontaminate livestock buildings from microorganisms of Nocardia and Rhodococcus genera.

\section{References}

Basybekov, S. Z., Bazarbayev, M. B., Yespembetov, B. A., Mussaeva, A., Kanatbayev, S. G., Romashev, K. M., Dossanova, A. K., Yelekeyev, T. A., Akmatova, E. K., \& Syrym, N. S. (2018). Diagnostics of tuberculosis and differentiation of nonspecific tuberculin reactions in animals. Brazilian Journal of Microbiology, 49(2), 329-335.

Bocian, E., Grzybowska, W., \& Tyski, S. (2014). Evaluation of mycobactericidal activity of selected chemical disinfectants and antiseptics according to European standards. Medical Science Monitor, 20, 666-673.

Brown-Elliott, B. A., Brown, J. M., Conville, P. S., \& Wallace, R. J. (2006). Clinical and laboratory features of the Nocardia spp. based on current molecular taxonomy. Clinical Microbiology Reviews, 19(2), 259-282.

Dodd, P. J., Millington, K. A., Ghani, A. C., Mutsvangwa, J., Butterworth, A. E., Lalvani, A., \& Corbett, E. L. (2010). Interpreting tuberculin skin tests in a population with a high prevalence of HIV, tuberculosis, and nonspecific tuberculin sensitivity. American Journal of Epidemiology, 171(9), 1037-1045.

Festing, S., \& Wilkinson, R. (2007). The ethics of animal research. Talking Point on the use of animals in scientific research. EMBO Reports, 8(6), 526-530.

Gajdács, M., \& Urbán, E. (2020). The pathogenic role of Actinomyces spp. and related organisms in genitourinary infections: Discoveries in the new, modern diagnostic era. Antibiotics, 9, 524.

Giguère, S., Cohen, N. D., Chaffin, M. K., Hines, S. A., Hondalus, M. K., Prescott, J. F., \& Slovis, N. M. (2011). Rhodococcus equi: Clinical manifestations, virulence, and immunity. Journal of Veterinary Internal Medicine, 25(6), 1221-1230.

Goodfellow, M., \& Maldonado, L. A. (2006). The families Dietziaceae, Gordoniaceae, Nocardiaceae and Tsukamurellaceae. Prokaryotes, 3, 843-888.

Gürtler, V., Mayall, B. C., \& Seviour, R. (2004). Can whole genome analysis refine the taxonomy of the genus Rhodococcus? FEMS Microbiology Reviews, 28(3), 377-403.

Jeckel, S., Holmes, P., King, S., Whatmore, A. M., \& Kirkwood, I. (2011). Disseminated Rhodococcus equi infection in goats in the UK. The Veterinary Record, $169(2), 56$.

Jones, G. J., Hewinson, R. G., \& Vordermeier, H. M. (2010). Screening of predicted secreted antigens from Mycobacterium bovis identifies potential novel differential diagnostic reagents. Clinical and Vaccine Immunology, 17(9), 1344-1348.

Kabene, S., \& Baadel, S. (2019). Bioethics: A look at animal testing in medicine and cosmetics in the UK. Journal of Medical Ethics and History of Medicine, 12, 15.

Kamboj, M., \& Kalra, C., \& Kak, V. (2005). Rhodococcus equi brain abscess in a patient without HIV. Journal of Clinical Pathology, 58(4), 423-425.

Kelley, H. V., Waibel, S. M., Sidiki, S., Tomatis-Souverbielle, C., Scordo, J. M., Hunt, W. G., Barr, N., Smith, R., Silwani, S. N., Averill, J. J., Baer, S., Hengesbach, J., Yildiz, V. O., Pan, X., Gebreyes, W. A., Balada-Llasat, J. M., Wang, S. H., \& Torrelles, J. B. (2020). Accuracy of two point-of-care tests for rapid diagnosis of bovine tuberculosis at animal level using non-invasive specimens. Scientific Reports, 10(1), 5441 .

Kindermann, J., Karbiener, M., Leydold, S. M., Knotzer, S., Modrof, J., \& Kreil, T. R. (2020). Virus disinfection for biotechnology applications: Different effectiveness on surface versus in suspension. Biologicals, 64, 1-9.

Mahendra, P., \& Dave, P. (2016). Nocardiosis: An emerging infectious Actinomycetic disease of humans and animals. Journal of Microbiology and Microbial Technology, 1(2), 4 .

Masand, A., Kumar, N., \& Patial, V. (2015). Actinomycosis (lumpy jaw) in cow: A case report. Comparative Clinical Pathology, 24, 541-543.

Mc Carlie, S., Boucher, C. E., \& Bragg, R. R. (2020). Molecular basis of bacterial disinfectant resistance. Drug Resistance Updates, 48, 100672.

McNeil, M. M., \& Brown, J. M. (1994). The medically important aerobic actinomycetes: Epidemiology and microbiology. Clinical Microbiological Reviews, 7(3), $357-417$.

Medo, J., Hleba, L., Císarová, M., \& Soňa Javoreková, S. (2019). Antimicrobial activity of actinomycetes and characterization of actinomycin-producing strain KRG-1 isolated from Karoo, South Africa. Brazilian Joumal of Pharmaceutical Sciences, 55, e17249.

Michel, A. L. (2008). Mycobacterium fortuitum infection interference with $M y c o-$ bacterium bovis diagnostics: Natural infection cases and a pilot experimental infection. Joumal of Veterinary Diagnostic Investigation, 20, 501-503.

Nalapa, D. P., Muwonge, A., Kankya, C., \& Olea-Popelka, F. (2017). Prevalence of tuberculous lesion in cattle slaughtered in Mubende district, Uganda. BMC Veterinary Research, 13, 73.

Njenga, W. P., Mwaura, F. B., Wagacha, J. M., \& Gathuru, E. M. (2017). Methods of isolating Actinomycetes from the soils of Menengai Crater in Kenya. Archives of Clinical Microbiology, 8, 3 .
Nuru, A., Zewude, A., Mohammed, T., Wondale, B., Teshome, L., Getahun, M., Mamo, G., Medhin, G., Pieper, R., \& Ameni, G. (2017). Nontuberculosis mycobacteria are the major causes of tuberculosis like lesions in cattle slaughtered at Bahir Dar Abattoir, Northwestern Ethiopia. BMC Veterinary Research, 13, 237.

Paliy, A. P., Stegniy, B. T., Muzyka, D. V., Gerilovych, A. P., \& Korneykov, O. M. (2016). The study of the properties of the novel virucidal disinfectant. Agricultural Science and Practice, 3(3), 41-47.

Paliy, A. P., Zavgorodniy, A. I., Stegniy, B. T., \& Palii, A. P. (2020). Naukovometodychni osnovy kontrolyu rozrobky ta zastosuvannya zasobiv dezinfektsiyi [Scientific and methodological grounds for controlling the development and use of disinfectants]. Miskdruk, Kharkiv (in Ukrainian).

Parte, A. C., Sardà Carbasse, J., Meier-Kolthoff, J. P., Reimer, L. C., \& Göker, M. (2020). List of prokaryotic names with standing in nomenclature (LPSN) moves to the DSMZ. International Journal of Systematic and Evolutionary Microbiology, 70(11), 5607-5612.

Pearlman, O. (2019). Reviewing the use of glutaraldehyde for high-level disinfection by sonographers. Journal of Diagnostic Medical Sonography, 35(1), 49-57.

Ramos, D. F., Silva, P. E. A., \& Dellagostin, O. A. (2015). Diagnosis of bovine tuberculosis: Review of main techniques. Brazilian Journal of Biology, 75(4), $830-837$.

Sapkota, A., Thapa, A., Budhathoki, A., Sainju, M., Shrestha, P., \& Aryal, S. (2020). Isolation, characterization, and screening of antimicrobial-producing actinomycetes from soil samples. International Joumal of Microbiology, 2020, 2716584.

Shinoda, N., Mitarai, S., Suzuki, E., \& Watanabe, M. (2016). Disinfectant-susceptibility of multi-drug-resistant Mycobacterium tuberculosis isolated in Japan. Antimicrobial Resistance and Infection Control, 5, 3.

Shkromada, O., Skliar, O., Paliy, A., Ukko, L., Gerun, I., Naumenko, O., Ishchenko, K., Kysterna, O., Musiienko, O., \& Paliy, A. (2019). Development of measures to improve milk quality and safety during production. Eastern-European Journal of Enterprise Technologies, 3/11(99), 30-39.

Siavashifar, M., Rezaei, F., Motallebirad, T., Azadi, D., Absalan, A., Naserramezani, Z., Golshani, M., Jafarinia, M., \& Ghaffari, K. (2021). Species diversity and molecular analysis of opportunistic Mycobacterium, Nocardia and Rhodococcus isolated from the hospital environment in a developing country, a potential resources for nosocomial infection. Genes and Environment, 43(1), 2.

Sicuro, B. (2016). The use of formaldehyde for the disinfection of maternally incubited eggs of noble crayfish (Astacus astacus). International Aquatic Research, 8, 353-359.

Singh, V., Haque, S., Singh, H., Verma, J., Vibha, K., Singh, R., Jawed, A., \& Tripathi, K. M. (2016). Isolation, screening, and identification of novel isolates of actinomycetes from India for antimicrobial applications. Frontiers in Microbiology, 7, 1921.

Sullivan, D. C., \& Chapman, S. W. (2010). Bacteria that masquerade as fungi: Actinomycosis/Nocardia. Proceedings of the American Thoracic Society, 7(3), 216-221.

Tkachenko, A. A., Davydenko, P. O., Zazharskiy, V. V., \& Brygadyrenko, V. V. (2016). Biological properties of dissociative L- and other forms of Mycobacterium bovis. Visnyk of Dnipropetrovsk University, Biology, Ecology, 24(2), $338-346$.

Van Metre, D. C., Tennant, B. C., \& Whitlock, R. H. (2008). Infectious diseases of the gastrointestinal tract. Rebhun's Diseases of Dairy Cattle, 2008, 200-294.

Vázquez-Boland, J. A., Giguère, S., Hapeshi, A., MacArthur, I., Anastasi, E., \& Valero-Rello, A. (2013). Rhodococcus equi: The many facets of a pathogenic actinomycete. Veterinary Microbiology, 167, 9-33.

Vordermeier, M., Gordon, S. V., \& Hewinson, R. G. (2011). Mycobacterium bovis antigens for the differential diagnosis of vaccinated and infected cattle. Veterinary Microbiology, 151, 8-13.

West, A. M., Teska, P. J., Lineback, C. B., \& Oliver, H. F. (2018). Strain, disinfectant, concentration, and contact time quantitatively impact disinfectant efficacy. Antimicrobial Resistance and Infection Control, 7, 49.

Yamshchikov, A. V., Schuetz, A., \& Lyon, G. M. (2010). Rhodococcus equi infection. The Lancet Infectious Diseases, 10(5), 350-359.

Zavgorodnii, A. I., Bilushko, V. V., Kalashnyk, M. V., Pozmogova, S. A., \& Kalashnyk, N. V. (2018). Psevdoalerhichni reaktsiyi na tuberkulin u velykoyi rohatoyi khudoby [Pseudo-allergic reactions to tuberculin in cattle]. Veterinary Biotechnology, 32(2), 176-184 (in Ukrainian).

Zazharskyi, V. V., Davydenko, P. O., Kulishenko, O. M., Borovik, I. V., \& Brygadyrenko, V. V. (2019). Antimicrobial activity of 50 plant extracts. Biosystems Diversity, 27(2), 163-169.

Zazharskyi, V. V., Davydenko, P. O., Kulishenko, O. M., Borovik, I. V., Kabar, A. M., \& Brygadyrenko, V. V. (2020). Antibacterial and fungicidal effect of ethanol extracts from Juniperus sabina, Chamaecyparis lawsoniana, Pseudotsuga menziesii and Cephalotaxus harringtonia. Regulatory Mechanisms in Biosystems, 11(1), 105-109. 